Article

\title{
Swing Vibration Control of Suspended Structure Using Active Rotary Inertia Driver System: Parametric Analysis and Experimental Verification
}

\author{
Chunwei Zhang *(1) and Hao Wang(1) \\ School of Civil Engineering, Qingdao University of Technology, Qingdao 266033, China \\ * Correspondence: zhangchunwei@qut.edu.cn; Tel.: +86-0532-8507-1328
}

Received: 5 July 2019; Accepted: 31 July 2019; Published: 2 August 2019

Featured Application: The presented active control system aims to suppress the swing vibrations of suspended structures.

\begin{abstract}
The Active Rotary Inertia Driver (ARID) system is a novel vibration control system that can effectively mitigate the swing vibration of suspended structures. Parametric analysis is carried out using Simulink based on the mathematical model and the effectiveness is further validated by a series of experiments. Firstly, the active controller is designed based on the system mathematical model and the LQR (linear quadratic regulator) algorithm. Next, the parametric analysis is carried out using Simulink to study the key parameters such as the coefficient of the control algorithm, the rotary inertia ratio. Lastly, the ARID system control effectiveness and the parametric analysis results are further validated by the shaking table experiments. The effectiveness and robustness of the ARID system are well verified. The dynamic characteristics of this system are further studied, and the conclusions of this paper provide a theoretical basis for further development of such unique control system.
\end{abstract}

Keywords: suspended structures; swing vibration control; active control; Active Rotary Inertia Driver; shaking table experiment

\section{Introduction}

The pendular vibration of the suspended structures is a common form of motion. The swing of the crane hook belongs to this kind of motion. Generally, pendular vibration keeps for a long time because of small damping. Sometimes, the pendular angle will be very large if external excitation is close to the structural natural frequency, which poses a great threat to structures. Therefore, it is necessary to apply effective vibration control techniques to control the pendular vibration of suspended structures. Pendular vibration mainly includes three basic modes according to the relationship between the lifting point and moving direction of structures: swing motion mode, sway motion mode, swing and sway coupling motion mode [1].

Structural vibration control devices have been widely used in civil engineering, mechanical engineering, ocean engineering and aerospace over the past few decades [2-14]. The structural vibration problems are complex and diverse. Correspondingly, vibration control devices and theories for different problems were developed. Control techniques mainly include passive, active and semi-active control. Many studies and practices show that common passive control devices, such as the Tuned Mass Damper (TMD), have been commonly adopted due to their design simplicity, good control effectiveness and low cost [15-20]. The Particle Dampers (PDs) [21], Frictional Tuned Mass Damper (FTMD) $[22,23]$ and Tuned Liquid Damper (TLD) $[24,25]$ are also the most commonly used passive control techniques in earthquake engineering. Active Mass Dampers (AMDs) [26] were widely studied 
in civil engineering for their superior effectiveness and larger spectral bandwidth. The feasibility of AMD application on the civil structures and ocean engineering structures has been studied [27-32]. Semi-active systems have been developed over the past decades. They can alternate their parameters in real time to ensure a superior, low-energy and stale control performance [33-35].

Although these passive, active and semi-active dampers are reliable and efficient, and they can effectively reduce the responses of the civil structures under external excitations in many conditions, they are almost ineffective in the swing motion control of suspended structures. Some researchers concentrated on solving the similar problems of pendulum motions control $[36,37]$. They designed controllers [38], linear and nonlinear control algorithms [39], an optimal performance control scheme [40] and an adaptive output-based command shaping (AOCS) technique [41] for the vibrations of cranes. But the hanging points of these crane structures were not fixed, the control technologies that reduced the vibrations relied on the moving of the hanging points. The control technologies need enough moving space in the structural hanging point. However, the hanging points of many suspended structures are fixed, such as ship cranes. Their hanging points are fixed in the determined position. The suspended control technologies above are not suitable for the swing motion control of these structures. Then, the Tuned Rotary Inertia Damper (TRID) system was proposed. In the TRID system, the rotary mass inertia is attached to the suspended structure. The torsional spring element embedded with a damping mechanism is installed between the mass inertia and the structure. The mass inertia rotation can apply control torque/moment to structures. The effectiveness of the TRID system for swing motion control was verified by a series of theoretical analyses and experiments. However, the TRID system has some defects. It cannot work normally when the swing angle is very small. Furthermore, it has time lag effect and low robustness.

To solve this problem, the Active Rotary Inertia Driver (ARID) system is proposed in this paper, based on the TRID system. Compared with the common control devices that can apply control force to the structures, the ARID system can apply control torque to structures by the rotation of mass inertia. The mass inertia is driven by a motor according to the structural response in real time. The ARID system can work installed in the suspended structures, compared to the control technologies that work relying on the movement of hanging points. The ARID system can be used for suspended structures in which hanging points are fixed in determined positions. Moreover, the ARID system can work without relying on the structural responses, and it has better control effectiveness and robustness compared to the TRID system. To verify the effectiveness of the ARID system, a series of parametric analyses [42] and shaking table experiments are carried out.

The outline of this paper is as follows. First, the active controller is designed based on the system mathematical model and the LQR (linear quadratic regulator) algorithm. Second, the system parametric analyses are carried out using Simulink based on the mathematical model and the LQR controller. Finally, to verify the effectiveness of the system and results of the parametric analysis, a series of experiments are carried out using the Quanser Shake Table II. Furthermore, the numerical analyses of the experiments are also correspondingly carried out using Simulink.

\section{Mathematical Model and Controller Design}

\subsection{Mathematical Model}

In order to carry out the parametric analysis, the simplified analytical model of the suspended structure with the ARID system was developed, which is shown in Figure 1. The model consists of two degrees of freedom used as generalized coordinators, which are the structural swing angle $\theta$ and the mass inertia relative rotation angle $\phi$ with respect to the ground base. The length of the suspended structure is $l$. The suspended particle mass is $m$, and the structural damping coefficient is $c$. The ARID system rotary inertia mass is $m_{a}$, the rotary inertia is $J_{a}$, the rotational stiffness coefficient is $k_{a}$ and the damping coefficient is $\mathrm{c}_{\mathrm{a}}$. The acceleration at the suspended structure lifting point is $a_{x 0}(t)$, 
and the control torque is $M_{a}(t)$. The motion equations of the model were deduced based on Lagrangian principle as:

$$
\begin{aligned}
\left(m+m_{a}\right) l^{2} \ddot{\theta}+c \dot{\theta}+ & \left(m+m_{a}\right) g l \sin \theta \\
= & -\left(m+m_{a}\right) l \cos \theta a_{x 0}(t)+c_{t}(\dot{\varnothing}-\dot{\theta})+k_{t}(\varnothing-\theta)-M_{a}(t) \\
& J_{a} \ddot{\varnothing}+c_{t}(\dot{\varnothing}-\dot{\theta})+k_{t}(\varnothing-\theta)=M_{a}(t)
\end{aligned}
$$

where $J_{a}=m_{a} r^{2}, c=2\left[m+m_{a} l^{2}\right] \omega \xi, \omega=\sqrt{g / l}, c_{a}=2 m_{a} r^{2} \omega_{a} \xi_{a}$ and $\omega_{a}=\sqrt{k_{a} / J_{a}}$ are the needed parameters. $r$ is the radius of the mass inertia, $\xi$ is the structural damping ratio and $\xi_{a}$ is the ARID damping ratio. Generally, its damping force and torsion resistance are very small compared with control torques, which can be neglected ( $c_{a}$ and $k_{a}$ are 0$)$.

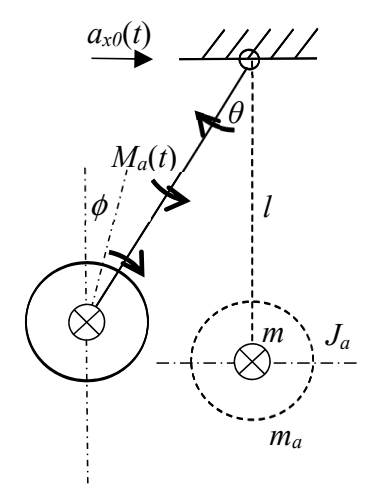

Figure 1. Simplified analysis model of the suspended structure with the ARID system.

\subsection{Parameter Identification}

There are two parameters reflecting control effectiveness, defined as:

$$
\begin{gathered}
\text { Peak }=\frac{\max \theta_{1}-\max \theta_{2}}{\max \theta_{1}} \\
R M S=\frac{s_{1}-s_{2}}{s_{1}}
\end{gathered}
$$

where $s$ is root-mean-square, $s=\left(\frac{1}{n} \sum_{i=1}^{n}\left(\theta_{i}-\bar{\theta}\right)^{2}\right)^{\frac{1}{2}}$ and $\bar{\theta}$ is angle mean, $\bar{\theta}=\frac{1}{n} \sum_{i=1}^{n} \theta_{i}, \theta_{i}$ is the angle of $i$ moment. $\theta_{1}$ is the swing angle without control. $\theta_{2}$ is the swing angle with the ARID control. $s_{1}$ is the root-mean-square without control. $s_{2}$ is the root-mean-square with the ARID control. The Peak reflects the control effect of the ARID system on a peak swing angle. The RMS (root-mean-square) reflects the control effect of the ARID system on swing angle dispersion.

\subsection{LQR Controller Design}

For the purpose of engaging the linear quadratic regulator (LQR) control algorithm, the motion equations were linearized. Generally, the clockwise swing angle is set as a positive value. In this paper, the swing angle $\theta$ was supposed to be very small. It was supposed that $\sin \theta \approx \theta, \cos \theta \approx 1$. Thus, the original nonlinear motion equations can be linearized and expressed into matrix form as:

$$
\left[\begin{array}{cc}
\left(m+m_{a}\right) l^{2} & 0 \\
0 & J_{a}
\end{array}\right]\left[\begin{array}{c}
\ddot{\theta} \\
\ddot{\varnothing}
\end{array}\right]+\left[\begin{array}{cc}
c & 0 \\
0 & 0
\end{array}\right]\left[\begin{array}{c}
\dot{\theta} \\
\dot{\varnothing}
\end{array}\right]+\left[\begin{array}{cc}
\left(m+m_{a}\right) g l & 0 \\
0 & 0
\end{array}\right]\left[\begin{array}{c}
\theta \\
\varnothing
\end{array}\right]=\left[\begin{array}{c}
-1 \\
1
\end{array}\right] M_{a}(t)-\left[\begin{array}{c}
\left(m+m_{a}\right) l \\
0
\end{array}\right] a_{x 0}
$$




$$
\begin{gathered}
\text { Set } \mathbf{M}=\left[\begin{array}{cc}
\left(m+m_{a}\right) l^{2} & 0 \\
0 & J_{a}
\end{array}\right], \mathbf{C}=\left[\begin{array}{cc}
c & 0 \\
0 & 0
\end{array}\right], \mathbf{K}=\left[\begin{array}{cc}
\left(m+m_{a}\right) g l & 0 \\
0 & 0
\end{array}\right], \mathbf{A}=\left[\begin{array}{cc}
0_{2 \times 2} & \mathbf{I}_{2} \\
-\mathbf{M}^{-1} \mathbf{K} & -\mathbf{M}^{-1} \mathbf{C}
\end{array}\right], \\
\mathbf{B}=\left[\begin{array}{c}
0_{2 \times 1} \\
\mathbf{M}^{-1} \mathbf{B}_{\mathbf{s}}
\end{array}\right], \mathbf{D}_{\mathbf{g}}=\left[\begin{array}{c}
0_{2 \times 1} \\
\mathbf{M}^{-1} \mathbf{D}_{\mathbf{s}}
\end{array}\right], \mathbf{B}_{\mathbf{s}}=\left[\begin{array}{c}
-1 \\
1
\end{array}\right], \mathbf{D}_{\mathbf{s}}=\left[\begin{array}{c}
\left(m+m_{a}\right) l \\
0
\end{array}\right] \\
Z(t)=(\theta(t), \varnothing(t), \dot{\theta}(t), \dot{\varnothing}(t))^{T}
\end{gathered}
$$

Thus, the motion equation can be written as follows:

$$
\dot{Z}(t)=\mathbf{A Z}(t)+\mathbf{B} M_{a}(t)+\mathbf{D}_{\mathbf{g}} a_{x 0}(t)
$$

When:

$$
\mathbf{Q}=\alpha\left[\begin{array}{cc}
\mathbf{K} & \mathbf{0}_{2 \times 2} \\
\mathbf{0}_{2 \times 2} & \mathbf{M}
\end{array}\right], \mathbf{R}=\beta \mathbf{I}, \mathbf{G}=\operatorname{lq} r(\mathbf{A}, \mathbf{B}, \mathbf{Q}, \mathbf{R})
$$

Therefore, based on the LQR algorithm, the active control torque is defined as follows:

$$
M_{a}(t)=-\mathbf{G Z}(t)
$$

Furthermore, the influence of $\mathrm{LQR}$ control algorithm parameters to control effectiveness curves are shown in Figure 2. When $\beta$ is constant, the control effectiveness becomes better as $\alpha$ increases. The value of the weighting matrix $\mathbf{Q}$ increases as $\alpha$ increases. In the reasonable value range of $\alpha$, the larger the $\mathbf{Q}$, the better the control effect will be. However, when $\alpha$ is constant, the control effectiveness becomes worse as $\beta$ increases.

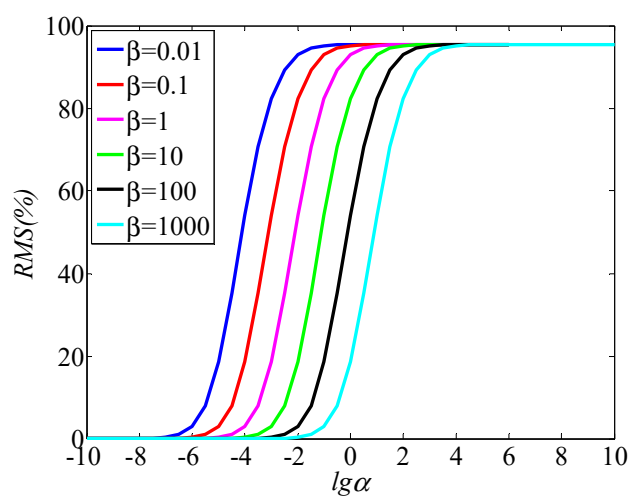

(a)

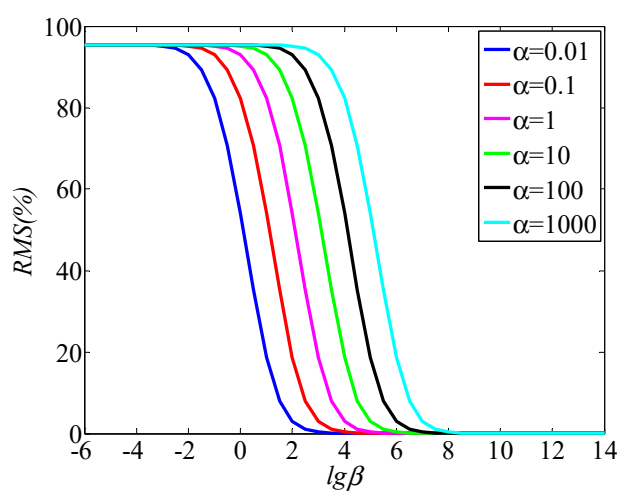

(b)

Figure 2. Effect of LQR parameters: (a) curves of $\alpha$; (b) curves of $\beta$.

\section{Parametric Analysis}

\subsection{Control Algorithm Parameter $\alpha$}

The parametric analyses were carried out by Simulink software. The influences of control algorithm parameter $\alpha$, rotary inertia ratio, mass ratio, suspended structural length ratio and excitation frequency are discussed in this part. The parameters mass ratio and rotary inertia ratio are determined as:

$$
r_{m}=\frac{m_{a}}{m+m_{a}}, r_{J}=\frac{m_{a} r^{2}}{\left(m+m_{a}\right) l^{2}}
$$

The parametric analysis curves of the LQR control algorithm parameter $\alpha$, rotary inertia ratio and mass ratio are shown in Figure 3. In the figures above, it can be found that: (a) When the rotary inertia ratio and mass ratio are different, the control effect curves are like steps. (b) When the $\alpha$ value 
is less than $10^{-8}$, the control effect is very bad. As the $\alpha$ value continues to decrease, the system loses the control effect. (c) When the value is greater than $10^{-8}$, the control effect becomes better as it increases. When the $\alpha$ value reaches $10^{-2}$, the control effect remains unchanged as it continues to increase. Figure 3a shows that when $\alpha$ is within the value range, the control effect becomes better as the rotary inertia ratio increases. Figure $3 \mathrm{~b}$ shows that when $\alpha$ is between the $10^{-8}$ and $10^{-2}$ interval, the control effect is more sensitive to $\alpha$. The control effect becomes better as the mass ratio decreases. When $\alpha$ is greater than $10^{-2}$, the optimal control effect is no longer related to the mass ratio. The system with a different mass ratio has the same control effect.

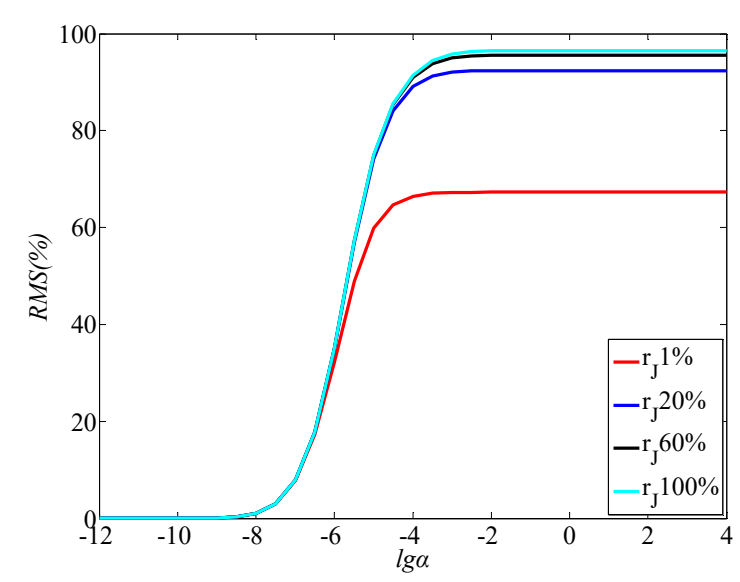

(a)

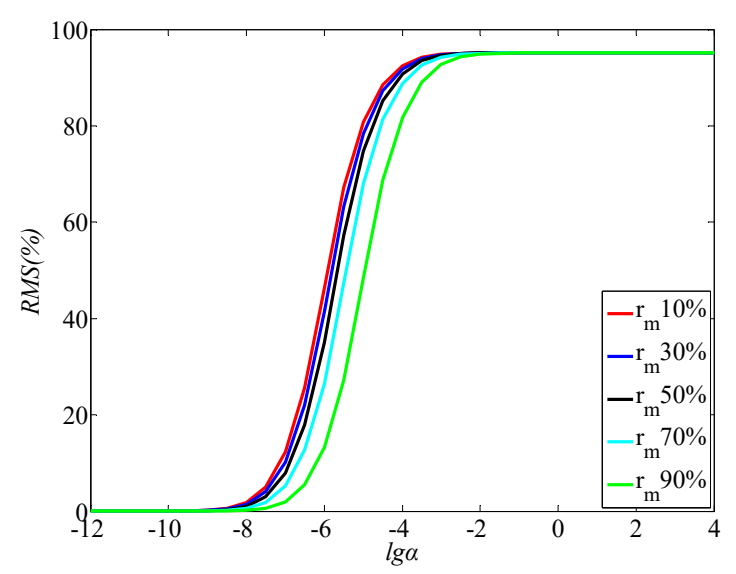

(b)

Figure 3. Effect of $\alpha$ on control effectiveness: curves of RMS.

\subsection{Rotary Inertia Ratio}

The influences of $r_{m}$ and $r_{J}$ to the control effectiveness are analyzed in this part. The results are shown in Figure 4. It can be concluded from the figure above that for the same rotary inertia ratio, the control effect becomes better as the mass ratio decreases. Furthermore, when the mass ratio is constant, the quantitative result changes monotonously. When the rotary inertia ratio is greater than 0.5 , the control effect increases slowly. The sensitivity of the rotary inertia ratio to the control effect decreases. 


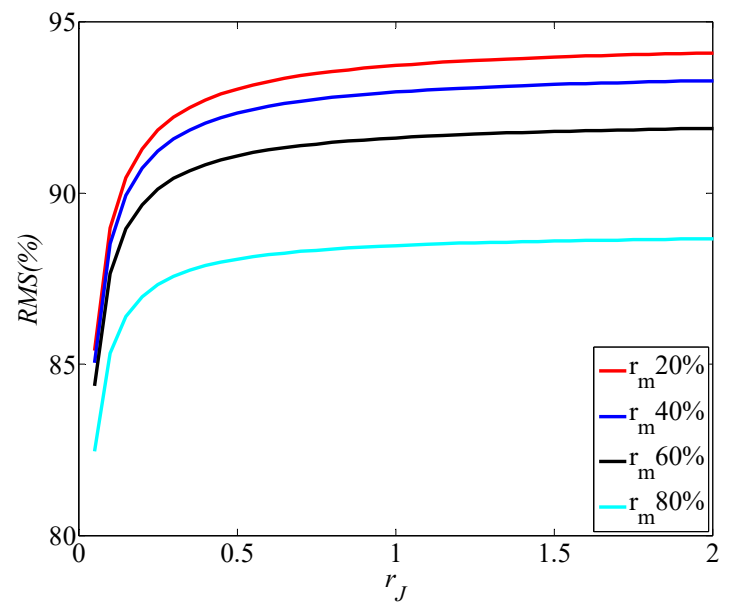

Figure 4. Effect of rotation inertia and mass on control effectiveness: curves of RMS.

\subsection{Mass Ratio}

The parameter radius ratio is defined as $r_{r}=r / l$. The parametric analysis curves of the mass ratio and the radius ratio are shown in Figure 5. It can be observed that when the mass ratio is constant, the control effect becomes better as the radius ratio increases. There is a coupling effect between the mass ratio and the radius ratio on the control effect. The variation of the fixed quantitative results is not monotonous. For the radius ratio of $40 \%, 60 \%$ and $80 \%$, when the mass ratio is less than 0.6 , the control effect increases with the mass ratio. When the mass ratio is greater than 0.6 , the control effect begins to decrease as the mass ratio increases. However, when the mass ratio is less than 0.8 , the control effect increases as the mass ratio increases for the radius ratio of $20 \%$. When it exceeds 0.8 , it decreases as the mass ratio increases. For different radius ratios, when the mass ratio is greater than 0.9 , as the mass ratio continues to increase, the control effect decays faster. Therefore, the reasonable interval of the mass ratio parameter is between 0.4 and 0.9 .

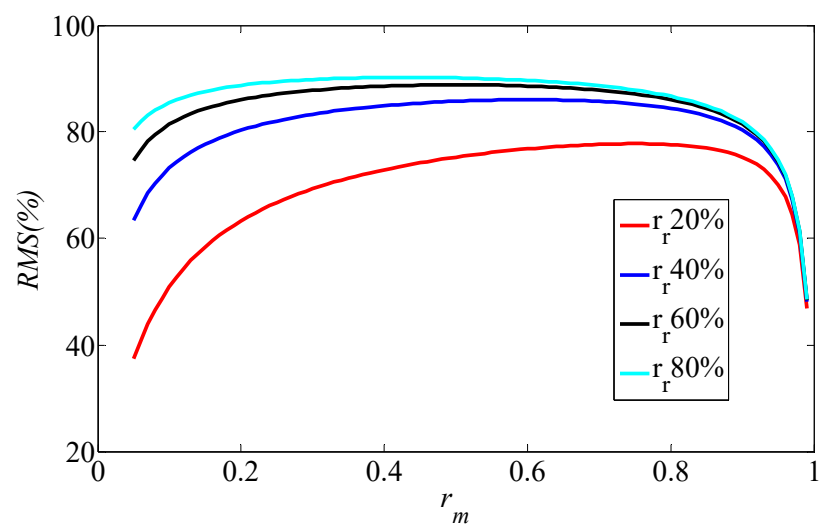

Figure 5. Effect of mass ratio on control effectiveness: curves of RMS.

\subsection{Suspended Structural Length Ratio}

The parametric analysis curves of the mass ratio and the suspended structural length ratio are shown in Figure 6. The length ratio is defined as $r_{l}=L / l . l$ is the suspended structure origin design length, and $L$ is an optimized design length. In Figure 6, it can be found that: (a) When the length ratio is constant, the control effect changes but not monotonously. The control effects at $40 \%$ and $60 \%$ are better than at $20 \%$ and $80 \%$. (b) When the mass ratio is constant, the influence of the length ratio has an optimal value point. The optimal length ratio value is about 0.9 . When the length ratio is greater than this value, the control effect gradually decreases as the length ratio increases. 


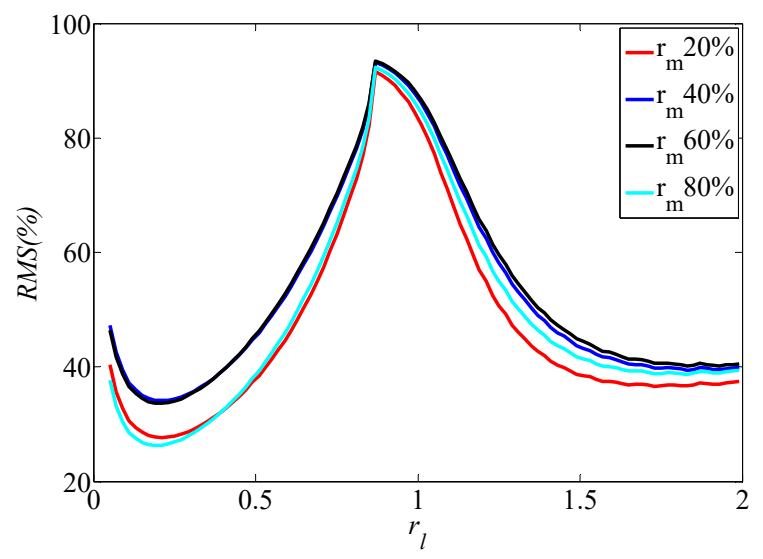

Figure 6. Effect of length on control effectiveness: curves of RMS.

\subsection{Excitation Frequency}

The structural natural frequency can be obtained by $\omega_{m}=\sqrt{g / l}$. $\lambda$ is defined as $\lambda=\omega / \omega_{m} . \omega$ is the excitation frequency. The sinusoidal excitation frequency applied to the structure is defined as the excitation frequency. The influence of the excitation frequency on the control effect is analyzed as shown in Figure 7. It can be found that the control effect achieves peak value at an excitation frequency. The frequency is close to the structural natural frequency. When the excitation frequency is higher than the optimal frequency point, the control effect decreases as the excitation frequency increases.

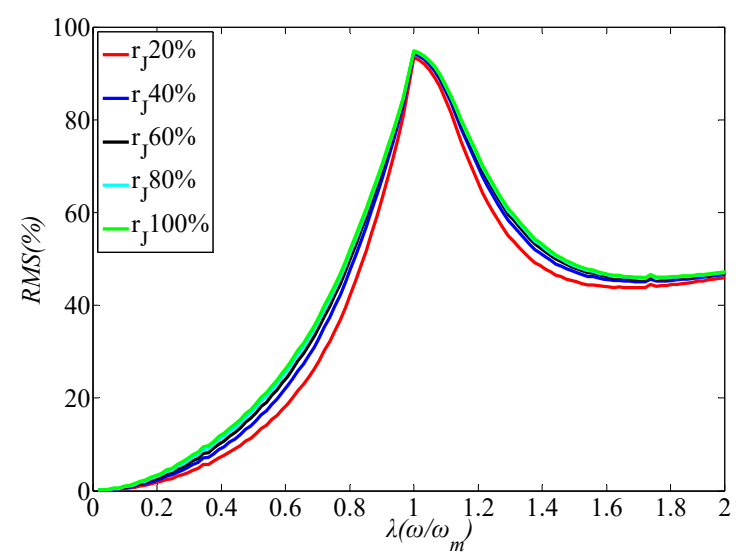

Figure 7. Effect of excitation frequency on control effectiveness: curves of RMS.

\section{Shaking Table Experiment}

The performance of the ARID system was evaluated by the shaking table experiments. The ARID system experimental device was designed as shown in Figures 8 and 9. The length of the suspended structure was $650 \mathrm{~mm}$. The natural frequency was around $0.64 \mathrm{~Hz}$. The shaking table can apply different frequency excitation to the suspended structure, and the swing angle was recorded by an encoder installed at the suspension point. 


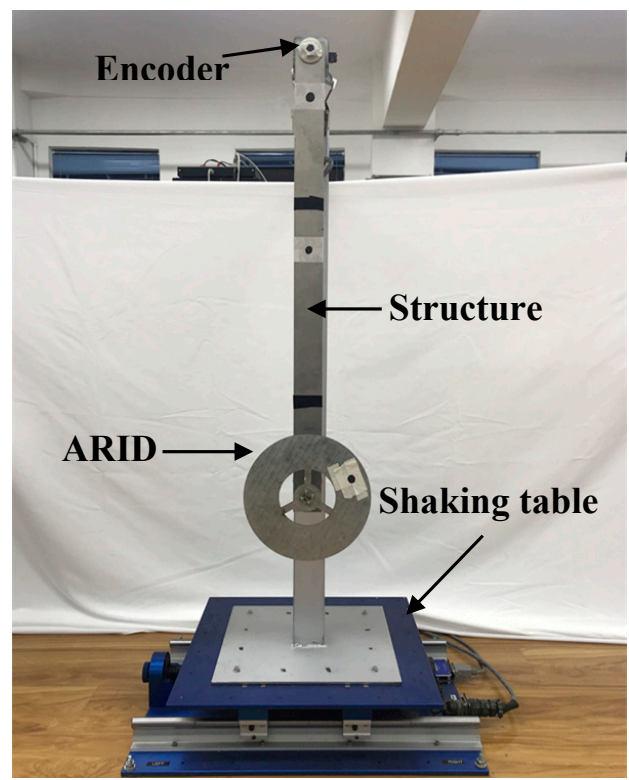

(a)

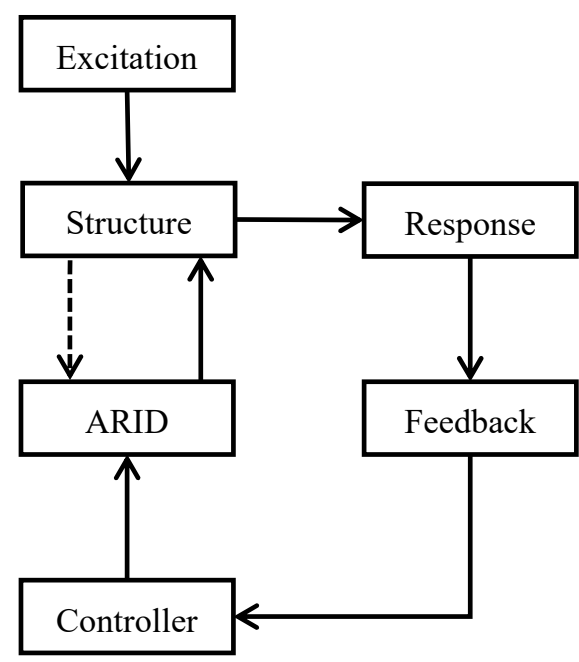

(b)

Figure 8. Sketch of experimental system: (a) photo of experiment setup; (b) control structure interaction loop of the ARID system.

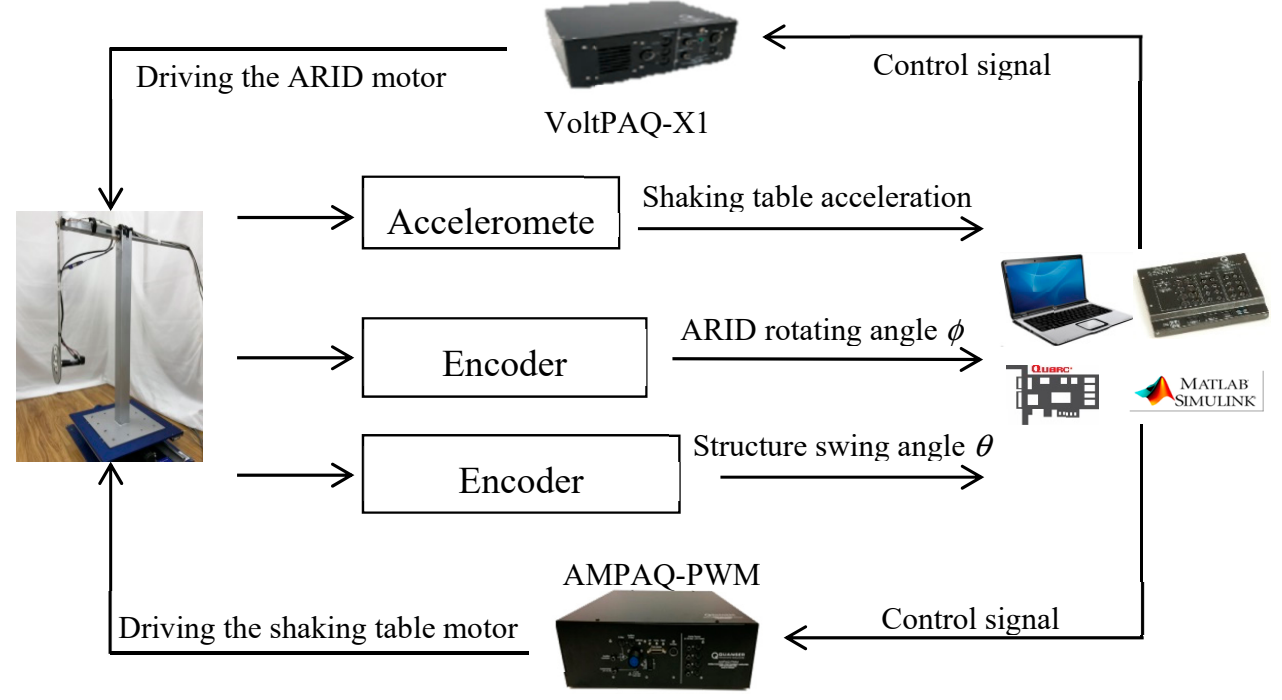

Figure 9. Schematic of the experiment system.

The shaking table was the Quanser single-axis Shaking Table II. The actuator was the Maxon DC motor and planetary gearbox. The motor-rated voltage was $24 \mathrm{~V}$. The data acquisition devices were the US Digital encoder and Maxon encoder. They were used to collect the swing angle and motor rotation angle, respectively. And the sampling resolutions of the encoders were $0.0879^{\circ}$ and $0.18^{\circ}$, respectively.

\subsection{Forced Sinusoidal Vibration}

We carried out 11 sets of experiments at different frequencies and the excitation magnitude was $10 \mathrm{~mm}$. Moreover, the numerical analyses were correspondingly carried out using Simulink. The swing angle time history curves are shown in Figure 10. $\lambda$ is defined as before. $\beta$ is defined by $\beta=\omega_{a} / \omega_{m}$. $\omega_{a}$ is the peak frequency obtained by frequency domain analysis. 


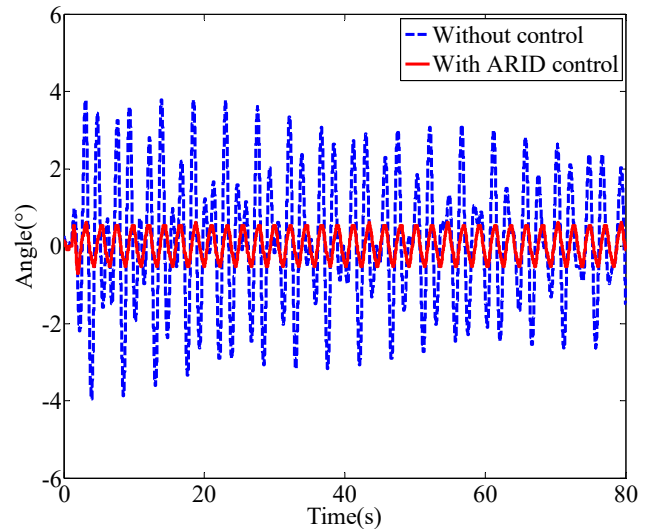

(a)

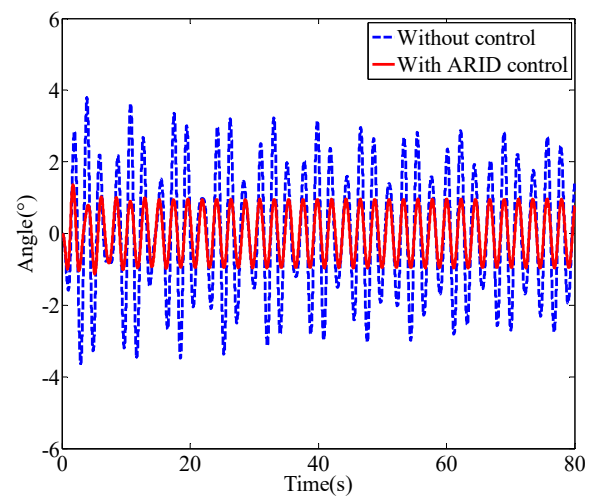

(c)

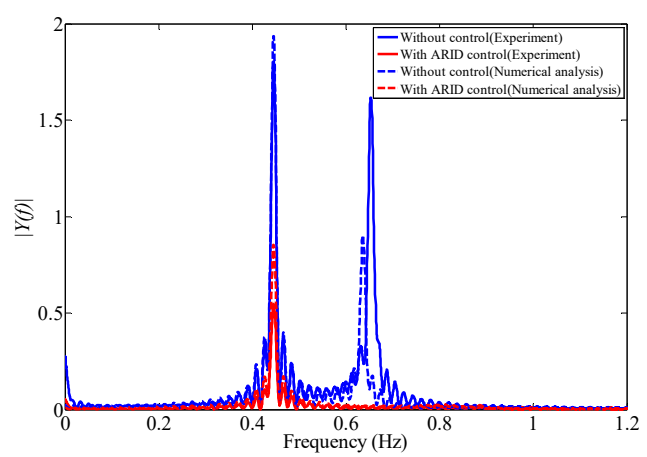

(e)

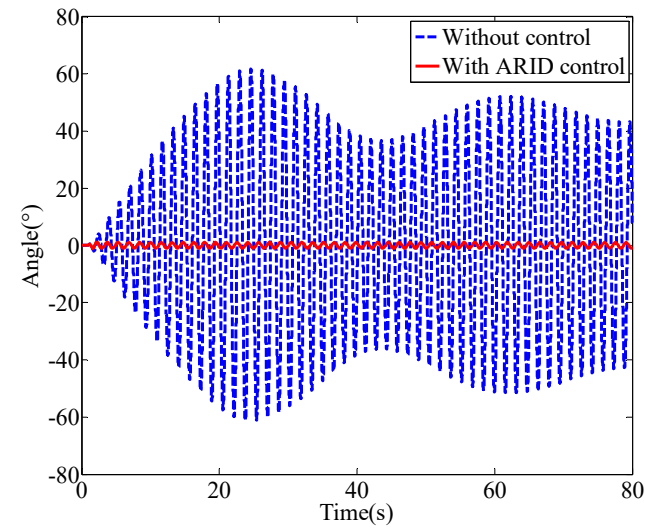

(b)

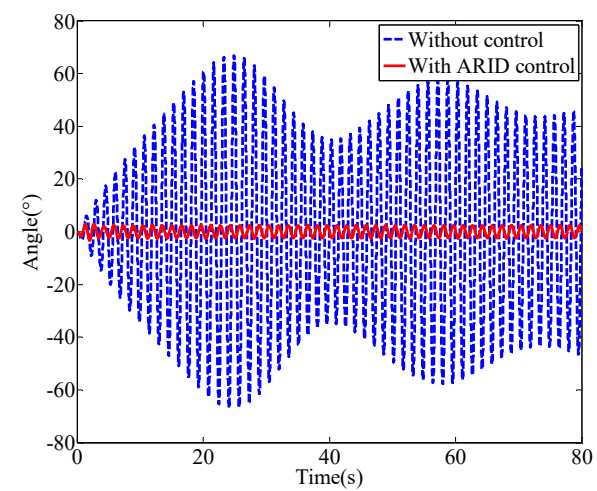

(d)

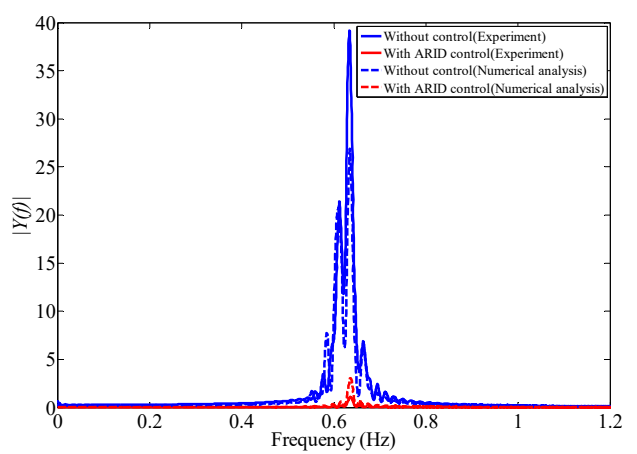

(f)

Figure 10. Comparison of experiment and numerical analysis results: (a) Experiment swing angle time history of $\lambda=0.7$; (b) Experiment swing angle time history of $\lambda=1$; (c) Numerical analysis swing angle time history of $\lambda=0.7$; (d) Numerical analysis swing angle time history of $\lambda=1$; (e) Amplitude-frequency curve of $\lambda=0.7$; (f) Amplitude-frequency curve of $\lambda=1$.

Figure $10 \mathrm{a}, \mathrm{c}$ show that the swing angle of the structure with ARID control was smaller. The control effect is obvious. And the numerical analysis results agree well with the experimental results, which can further prove the good control effect of the ARID system. Figure 10b,d show that there were two peaks in the frequency domain without a control case, while in the ARID control case, there was only one peak. The results of the numerical analysis also agree well with the experimental results. The 11 sets of frequency domain analysis results are shown in Figure 11. 


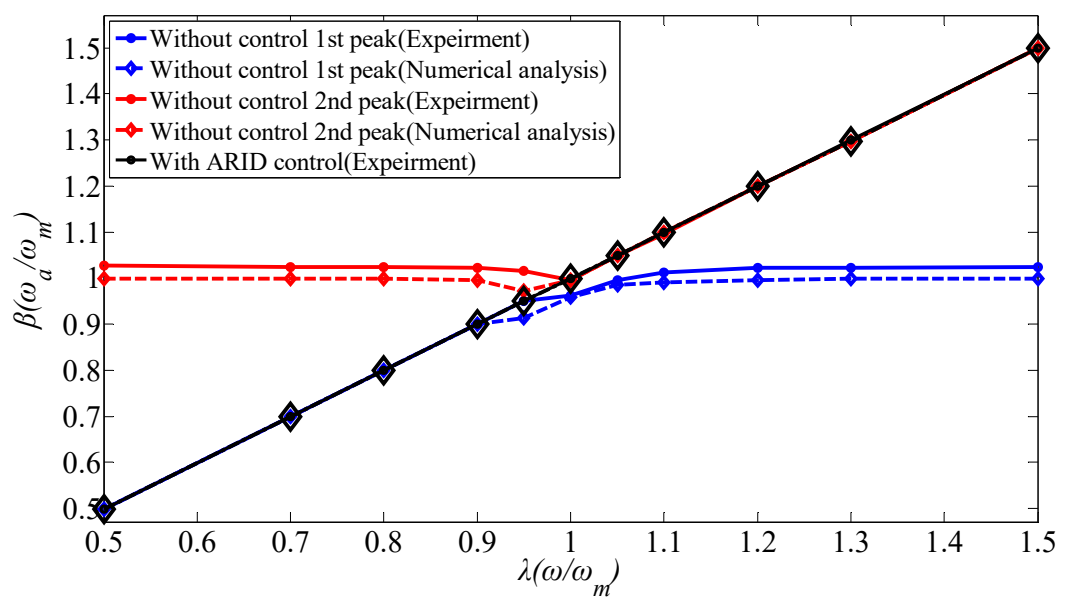

Figure 11. Frequency domain analysis diagram of the experiment and numerical analysis.

In Figure 10, it can be found that: (a) The two peaks in the frequency domain are the excitation frequency and the natural structural frequency of the structure without control. When the excitation frequency is smaller than the natural structural frequency, the first peak frequency is closed to the excitation frequency, and the second peak frequency is closed to the natural structural frequency. When the excitation frequency is greater than the natural structural frequency, the first peak frequency is closed to the natural structural frequency, and the second peak frequency is closed to the excitation frequency. (b) In the ARID controlled case, there is only one peak in the frequency domain. The peak frequency is closed to the excitation frequency. This result indicates that the ARID system completely suppresses the structural response at the natural structural frequency. Furthermore, it can be found that the structural spectral energy is significantly reduced at the excitation frequency. It can be inferred that the ARID system consumes the natural structural frequency energy as well as the external excitation energy.

Furthermore, it can be found from Figure 10a that the ARID system has good control effect even though the swing angle is very small. It can be verified that the ARID system has better robustness and effectiveness than the TRID system.

Figure 12 shows the peak swing angle curves of structures with ARID control and without control. The peak swing angle of structures with ARID control is smaller. There is a good agreement between the experimental results and numerical analysis results. It can be proved that the ARID system can reduce the maximum response of the structure. Moreover, when the external excitation is close to the structural natural frequency, the peak swing angle is larger. In this case, the peak swing angle of structures with ARID control is much smaller. It can be proved that the control system can effectively reduce the structural response under the most unfavorable excitation conditions. 


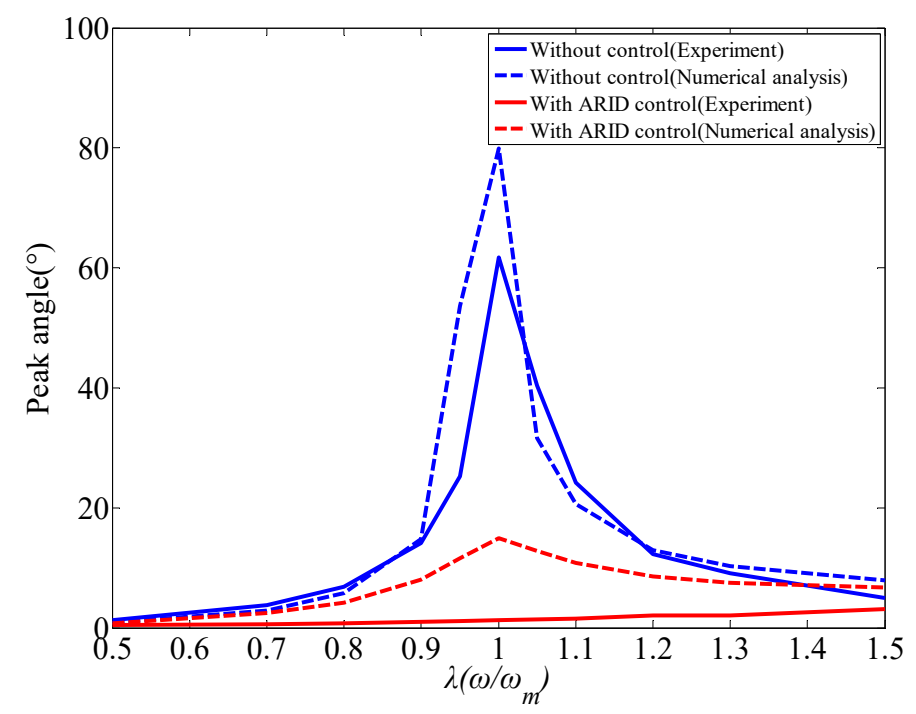

Figure 12. Peak swing angle of experiment and numerical analysis.

Figure 13 shows that the control effect of the ARID system is close to the peak value when the excitation frequency is close to the structure natural frequency. It is proved that the ARID system has control effects under different excitations. The most obvious control effect is under unfavorable excitation conditions.

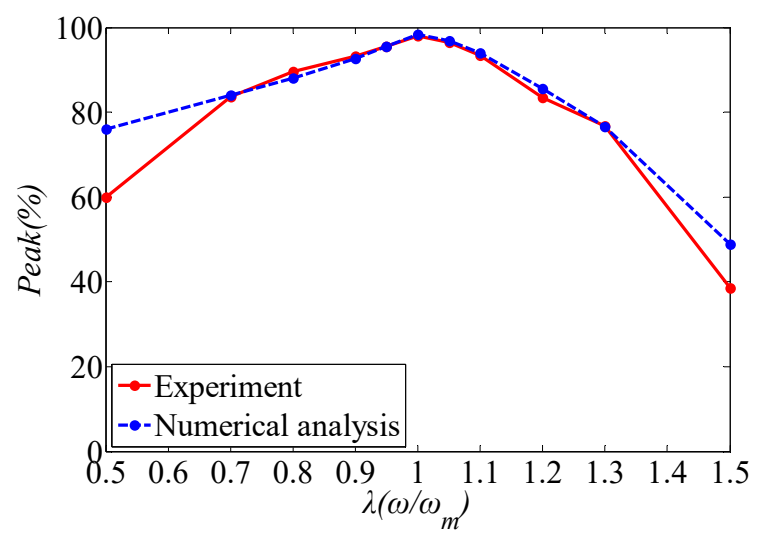

Figure 13. Control effectiveness of experiment and numerical analysis.

\subsection{Resonance Harmonic Excitation and Free Decay Vibration}

In this section, the control effectiveness of different rotary inertia is studied. The total sampling time was $40 \mathrm{~s}$. The structures were under resonance harmonic excitation in the first $15 \mathrm{~s}$ and then decayed freely. The excitation magnitude was $20 \mathrm{~mm}$, and the frequency was closed to the natural structural frequency. The parameters of rotary inertia are shown in Table 1.

Table 1. Parameters of rotary inertia.

\begin{tabular}{ccccc}
\hline No. & Mass $(\mathbf{g})$ & Radius $(\mathbf{m m})$ & $\boldsymbol{J} \mathbf{( g \cdot \mathbf { m m } ^ { \mathbf { 2 } } )}$ & $\boldsymbol{r}_{\boldsymbol{J}}\left(\times \mathbf{1 0}^{-\mathbf{3}}\right)$ \\
\hline 1 & 69 & 50 & 98,465 & 0.5 \\
2 & 107 & 75 & 378,318 & 1.7 \\
3 & 423 & 100 & $2,308,657$ & 6.8 \\
4 & 205 & 150 & $3,224,167$ & 13 \\
5 & 744 & 130 & $6,645,262$ & 14 \\
\hline
\end{tabular}


Figure 14 shows the comparison of the experimental and numerical analysis results of No. 1 and No. 3. It can be seen that the effectiveness of No.3 is better than No.1. The response of the structure with ARID control was completely controlled during the sampling time. Furthermore, from the amplitude-frequency curves in Figure 14e,f, it can be seen that the ARID system can suppress the spectral energy at a natural structural frequency effectively. The control effectiveness results of structures with different rotary inertia are shown in Figure 15. It can be seen that the control effectiveness becomes better as the rotary inertia ratio increases. And it agrees well with the conclusion of the parameter analysis results as before.

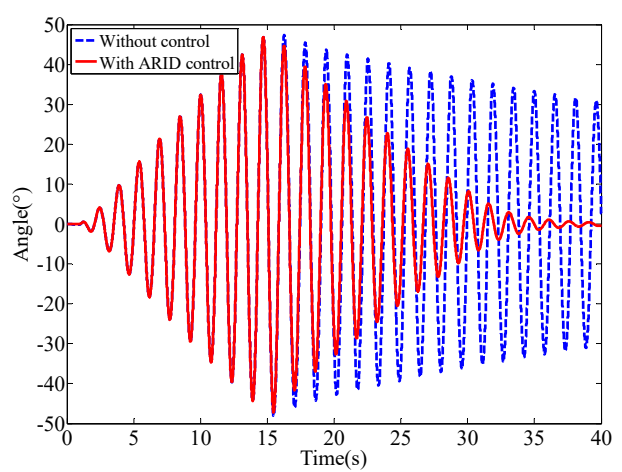

(a)

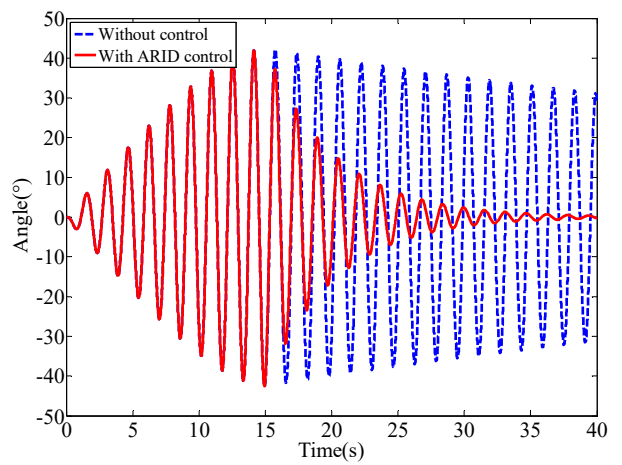

(c)

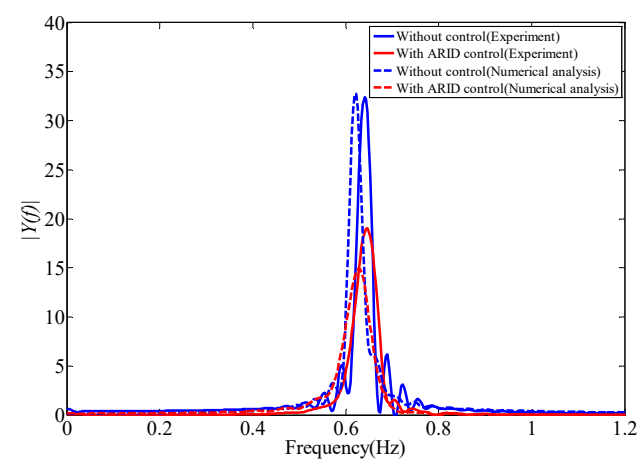

(e)

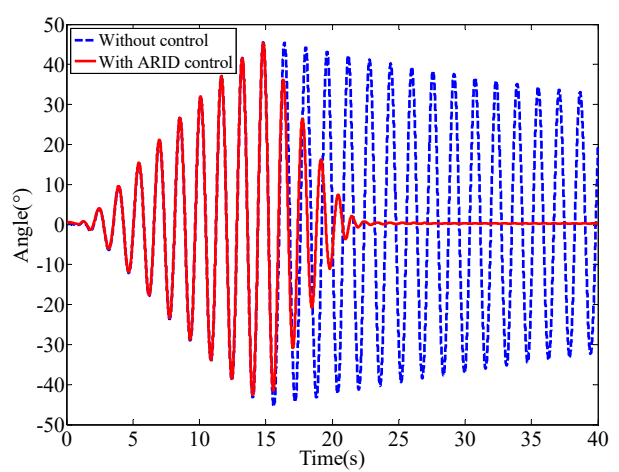

(b)

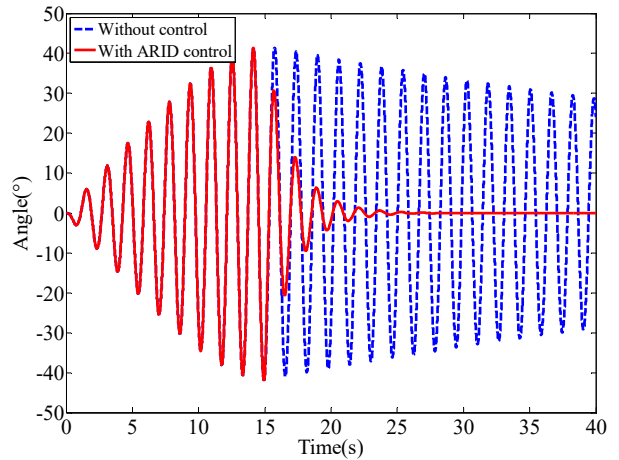

(d)

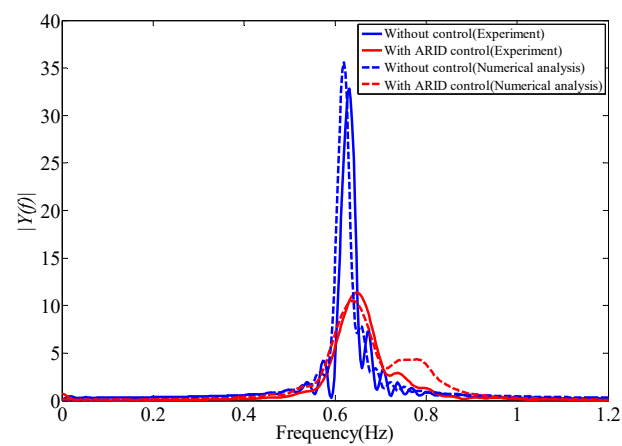

(f)

Figure 14. Comparison of experiment and numerical analysis results: (a) Experiment swing angle time history of No.1; (b) Experiment swing angle time history of No.3; (c) Numerical analysis swing angle time history of No.1; (d) Numerical analysis swing angle time history of No.3; (e) Amplitude-frequency curve of No.1; (f) Amplitude-frequency curve of No.3. 


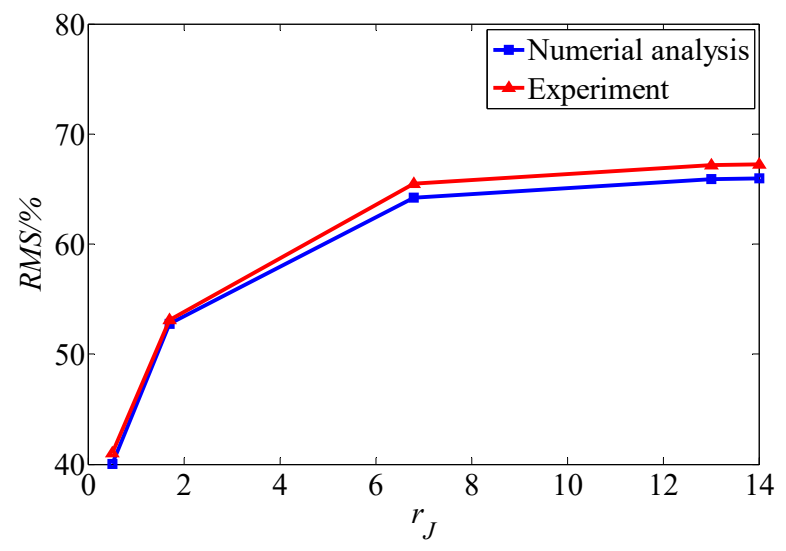

Figure 15. Comparison of experimental and numerical analysis results.

\section{Conclusions}

In this paper, the proposed ARID system was studied. The parametric analyses were carried out using Simulink and a series of shaking table experiments were performed to verify the control effectiveness and parametric analysis results. According to the experiments and numerical analysis results, the following conclusions can be achieved:

(1) The effectiveness and feasibility of the proposed ARID system for the swing vibration control are verified. It has better control effectiveness and robustness as compared with the TRID system. It can effectively reduce the vibration of suspended structures when positions of the hanging points are determined.

(2) The parametric analysis and experimental verification of the ARID system can provide theoretical foundations for the designs of the system.

(3) The ARID system consumes the natural structural frequency energy and external excitation energy. Moreover, the system can effectively reduce the structural response under the most unfavorable excitation.

(4) The feasibility of the ARID system for torsional swing vibration control, such as the flutter of long-span bridges and the torsion of high-speed railway trains, is meaningful to further research. Furthermore, it is necessary to study the control cost of the ARID system by optimizing the control algorithms.

Author Contributions: C.Z. initiated the problem, proposed the idea, defined the research essentials, conceived the method, and revised the paper. H.W. carried out the theoretical research, parametric study, experiments and prepared the draft.

Funding: The research is financially supported by the Ministry of Science and Technology of China (Grant No. 2017YFC0703603), the National Natural Science Foundation of China (Grant No. 51678322 and 51650110509), the Taishan Scholar Priority Discipline Talent Group program funded by the Shandong Province, and the first-class discipline project funded by the Education Department of Shandong Province.

Conflicts of Interest: The authors declare no conflict of interest.

\section{References}

1. Zhang, C.; Li, L.; Ou, J. Swinging motion control of suspended structures: Principles and applications. Struct. Control Health 2010, 17, 549-562. [CrossRef]

2. Xu, H.; Zhang, C.; Li, H.; Tan, P.; Ou, J.; Zhou, F. Active mass driver control system for suppressing wind induced vibration of the Canton Tower structure. Smart Struct. Syst. 2014, 13, 281-303. [CrossRef]

3. Palacios-Quiñonero, F.; Rubió-Massegú, J.; Rossell, J.M.; Karimi, H.R. Integrated Design of Hybrid Interstory-Interbuilding Multi-Actuation Schemes for Vibration Control of Adjacent Buildings under Seismic Excitations. Appl. Sci. 2017, 7, 323. [CrossRef] 
4. Shi, W.; Wang, L.; Lu, Z. Study on self-adjustable tuned mass damper with variable mass. Struct. Control Health 2018, 25, e2114. [CrossRef]

5. Suarez, E.; Roldán, A.; Gallego, A.; Benavent-Climent, A. Entropy Analysis for Damage Quantification of Hysteretic Dampers Used as Seismic Protection of Buildings. Appl. Sci. 2017, 6, 628. [CrossRef]

6. Zhang, C.; Ou, J.; Zhang, J. Parameter Optimization and Analysis of Vehicle Suspension System Controlled by Magnetorheological Fluid Dampers. Struct. Control Health 2006, 13, 885-896.

7. Chen, S.R.; Cai, C.S. Coupled vibration control with tuned mass damper for long-span bridges. J. Sound Vib. 2004, 278, 449-459. [CrossRef]

8. Wang, W.; Dalton, D.; Hua, X.; Wang, X.; Chen, Z.; Song, G. Experimental Study on Vibration Control of a Submerged Pipeline Model by Eddy Current Tuned Mass Damper. Appl. Sci. 2017, 7, 987. [CrossRef]

9. Song, G.; Cai, S.C.S.; Li, H. Energy Dissipation and Vibration Control: Modeling, Algorithm, and Devices. Appl. Sci. 2017, 7, 801. [CrossRef]

10. Li, H.; Song, G.; Kim, J.T.; Li, G. Smart Control Algorithms and Technology in Civil Infrastructures. Math. Probl. Eng. 2014, 2014, 1-2. [CrossRef]

11. Wang, L.; Shi, W.; Li, X.; Zhang, Q.; Zhou, Y. An adaptive-passive retuning device for a pendulum tuned mass damper considering mass uncertainty and optimum frequency. Struct. Control Health 2019, $26, \mathrm{e} 2377$. [CrossRef]

12. Pietrosanti, D.; De Angelis, M.; Basili, M. Optimal design and performance evaluation of systems with Tuned Mass Damper Inerter (TMDI). Earthq. Eng. Struct. Dyn. 2017, 46, 1367-1388. [CrossRef]

13. Huang, C.; Huo, L.; Gao, H.; Li, H. Control performance of suspended mass pendulum with the consideration of out-of-plane vibrations. Struct. Control Health 2018, 25, e2217. [CrossRef]

14. Fitzgerald, B.; Sarkar, S.; Staino, A. Improved reliability of wind turbine towers with active tuned mass dampers (ATMDs). J. Sound Vib. 2018, 419, 103-122. [CrossRef]

15. Zuo, H.; Bi, K.; Hao, H. Using multiple tuned mass dampers to control offshore wind turbine vibrations under multiple hazards. Eng. Struct. 2017, 141, 303-315. [CrossRef]

16. Matta, E. A novel bidirectional pendulum tuned mass damper using variable homogeneous friction to achieve amplitude-Independent control. Earthq. Eng. Struct. Dyn. 2019, 48, 653-667. [CrossRef]

17. Zhang, C. Control Force Characteristics of Different Control Strategies for the Wind-excited 76-story Benchmark Building Structure. Adv. Struct. Eng. 2014, 17, 543-559. [CrossRef]

18. Wang, W.; Hua, X.; Chen, Z.; Wang, X.; Song, G. Modeling, simulation, and validation of a pendulum-pounding tuned mass damper for vibration control. Struct. Control Health 2019, 26, e2326. [CrossRef]

19. Yin, X.; Song, G.; Liu, Y. Vibration Suppression of Wind/Traffic/Bridge Coupled System Using Multiple Pounding Tuned Mass Dampers (MPTMD). Sensors 2019, 19, 1133. [CrossRef]

20. Ferreira, F.; Moutinho, C.; Cunha, Á.; Caetano, E. Proposal of optimum tuning of semiactive TMDs used to reduce harmonic vibrations based on phase control strategy. Struct. Control Health 2018, 25, e2131. [CrossRef]

21. Papalou, A.; Strepelias, E. Effectiveness of particle dampers in reducing monuments response under dynamic loads. Mech. Com. Mater. Struct. 2016, 23, 128-135. [CrossRef]

22. Jiang, J.; Ho, S.C.M.; Markle, N.J.; Wang, N.; Song, G. Design and control performance of a frictional tuned mass damper with bearing-shaft assemblies. J. Vib. Control 2019, 25, 1812-1822. [CrossRef]

23. Pisal, A.Y.; Jangid, R.S. Vibration control of bridge subjected to multi-axle vehicle using multiple tuned mass friction dampers. Int. J. Adv. Struct. Eng. 2016, 8, 213-227. [CrossRef]

24. Banerji, P.; Murudi, M.; Shah, A.H.; Popplewell, N. Tuned liquid dampers for controlling earthquake response of structures. Earthq. Eng. Struct. Dyn. 2015, 29, 587-602. [CrossRef]

25. Shum, K.M.; Xu, Y.L. Multiple tuned liquid column dampers for reducing coupled lateral and torsional vibration of structures. Eng. Struct. 2004, 26, 745-758. [CrossRef]

26. Preumont, A. Vibration Control of Active Structures: An Introduction; Springer: Berlin/Heidelberg, Germany, 2018; Volume 246.

27. Venanzi, I.; Ierimonti, L.; Ubertini, F. Effects of control-structure interaction in active mass driver systems with electric torsional servomotor for seismic applications. Bull. Earthq. Eng. 2016, 15, 1543-1557. [CrossRef]

28. Zhang, C.; Ou, J. Modeling and dynamical performance of the electromagnetic mass driver system for structural vibration control. Eng. Struct. 2015, 82, 93-103. [CrossRef]

29. Zhang, C.; Ou, J. Control Structure Interaction of Electromagnetic Mass Damper System for Structural Vibration Control. J. Eng. Mech. ASCE 2008, 134, 428-437. 
30. May, B.S.; Beck, J.L. Probabilistic control for the Active Mass Driver benchmark structural model. Earthq. Eng. Struct. Dyn. 2015, 27, 1331-1346. [CrossRef]

31. Xu, H.; Zhang, C.; Li, H.; Ou, J. Real-time hybrid simulation approach for performance validation of structural active control systems: A linear motor actuator based active mass driver case study. Struct. Control Health 2014, 21, 574-589. [CrossRef]

32. Camachogómez, C.; Wang, X.; Pereira, E.; Díaz, I.M.; Salcedo-Sanz, S. Active vibration control design using the Coral Reefs Optimization with Substrate Layer algorithm. Eng. Struct. 2018, 157, 14-26. [CrossRef]

33. Ho, C.; Zhu, Y.; Lang, Z.Q.; Billings, S.A.; Kohiyama, M.; Wakayama, S. Nonlinear damping based semi-active building isolation system. J. Sound Vib. 2018, 424, 302-317. [CrossRef]

34. Chey, M.H.; Chase, J.G.; Mander, J.B.; Carr, A.J. Semi-active tuned mass damper building systems, Design. Earthq. Eng. Struct. Dyn. 2010, 39, 119-139. [CrossRef]

35. Behrooz, M.; Wang, X.; Gordaninejad, F. Modeling of a new semi-active/passive magneto rheological elastomer isolator. Smart Mater. Struct. 2014, 23, 045013. [CrossRef]

36. Pappalardo, C.; Guida, D. Use of the Adjoint Method for Controlling the Mechanical Vibrations of Nonlinear Systems. Mach 2018, 6, 19. [CrossRef]

37. Bertolazzi, E.; Biral, F.; Da Lio, M. Symbolic-numeric indirect method for solving optimal control problems for large multibody systems. Multibody Syst. Dyn. 2005, 13, 233-252. [CrossRef]

38. Mori, Y.; Tagawa, Y. Vibration controller for overhead cranes considering limited horizontal acceleration. Control Eng. Pract. 2018, 81, 256-263. [CrossRef]

39. Hamza, M.F.; Yap, H.J.; Choudhury, I.A.; Isa, A.I.; Zimit, A.Y.; Kumbasar, T. Current development on using Rotary Inverted Pendulum as a benchmark for testing linear and nonlinear control algorithms. Mech. Syst. Signal Process. 2019, 116, 347-369. [CrossRef]

40. Maghsoudi, M.J.; Mohamed, Z.; Husain, A.R.; Tokhi, M.O. An optimal performance control scheme for a 3D crane. Mech. Syst. Signal Process. 2016, 66-67, 756-768. [CrossRef]

41. Abdullahi, A.M.; Mohamed, Z. Adaptive output-based command shaping for sway control of a 3D overhead crane with payload hoisting and wind disturbance. Mech. Syst. Signal Process. 2018, 98, 157-172. [CrossRef]

42. Kirk, D.E. Optimal Control Theory: An Introduction; Dover Publications, Inc.: Mineola, New York, NY, USA, 2012.

(C) 2019 by the authors. Licensee MDPI, Basel, Switzerland. This article is an open access article distributed under the terms and conditions of the Creative Commons Attribution (CC BY) license (http://creativecommons.org/licenses/by/4.0/). 